\title{
Respiratory Therapy Faculty Knowledge of and Attitudes Toward Interprofessional Education
}

\author{
Marlo M Vernon MPH, Nicole M Moore MSc RD LD, Lisa-Anne Cummins MEd ATC CSCS, \\ Stephanie E Reyes MSc CCC-SLP, Andrew J Mazzoli PhD RRT, Vahe Heboyan PhD MPH, and \\ Gianluca De Leo PhD MBA
}

\begin{abstract}
BACKGROUND: Interprofessional education (IPE) improves collaboration and patient care through joint education between health professions. Respiratory therapy (RT) faculty were surveyed to evaluate their knowledge and attitudes toward IPE. We report current opportunities for IPE from faculty and compare responses from associate's, bachelor's, and master's degree programs and profit versus nonprofit institutions. METHODS: We developed an online survey based on IPE literature and questions modified for the RT discipline. The survey was distributed by email to 874 faculty from the Commission on Accreditation for Respiratory Care accredited programs. RESULTS: The response rate was $33 \%$. Faculty identified IPE as an important component of RT education $(n=207,80 \%)$ but reported challenges in integrating IPE into current curriculum. Overall, communication was ranked as the most important IPE competency $(n=104,39 \%)$ and ethics least important $(n=131,49 \%)$. When asked how many credit hours are required to teach IPE, $48 \%$ of respondents reported that they were unsure of an appropriate time requirement. Significant differences between associate's and bachelor's/master's degree program faculty were found on the following topics: institutional resources needed for IPE $(P<.001)$, faculty availability $(P<.001)$, curriculum availability for IPE $(P=.02)$, and importance of including IPE at academic health center campuses $(P<.001)$. CONCLUSIONS: IPE is recognized as an important component of $\mathrm{RT}$ education by all faculty respondents. However, significant differences in knowledge and attitudes toward IPE exist between faculty in associate's versus bachelor's/master's degree programs. Revisiting the current accreditation standards program may allow IPE to take a more prominent role in RT curricula. Key words: interprofessional education; curriculum; accreditation; competency-based education; teaching. [Respir Care 2017;62(7):873-881. (C) 2017 Daedalus Enterprises]
\end{abstract}

\section{Introduction}

Interprofessional education (IPE) occurs when 2 or more health professions learn with, from, and about each other

\footnotetext{
Ms Vernon, Ms Moore, Ms Cummins, and Ms Reyes are affiliated with the College of Allied Health Sciences, and Drs Mazzoli, Heboyan, and De Leo are affiliated with Clinical and Digital Health Sciences, College of Allied Health Sciences, Augusta University, Augusta, Georgia.

The authors have disclosed no conflicts of interest.

Supplementary material related to this paper is available at http:// www.rcjournal.com.

Correspondence: Marlo M Vernon MPH, College of Allied Health Sciences, Augusta University, 987 St. Sebastian Way, EC-3404, Augusta, Georgia 30912. E-mail: mvernon@augusta.edu.
}

DOI: $10.4187 /$ respcare.05034 to increase collaboration in the workplace and to improve the quality of patient care. ${ }^{1}$ Students learn how to function as part of an interprofessional team and are expected to carry collaborative skills into practice. ${ }^{2}$ In 2003 , the Institute of Medicine ${ }^{3}$ reported that patients receive safer and higher quality care when health-care professionals work effectively as a team, have proper communication, and understand each member's role. The Interprofessional Education Collaborative Expert Panel ${ }^{4}$ defines 4 core domains of competencies: (1) values/ethics for interprofessional practice; (2) roles/responsibilities; (3) interprofessional communication; and (4) teamwork. Although the IPEC Expert Panel ${ }^{4}$ involves a variety of health professionals, such as nursing, medicine, and pharmacy, it does not include respiratory therapy (RT) experts.

Respiratory therapists regularly function as an integral part of an interprofessional team composed of physicians, 
nurses, and other health-care professionals, both within and outside of the hospital setting. Responsibilities include diagnosing lung and breathing disorders, recommending treatment methods, managing ventilators, and educating patients and families about lung disease. Close to 120,000 RT professionals currently work in health care, and RT job

\section{See the Related Editorial on Page 999}

openings have increased $19 \%$ since $2012 . .^{5}$ It is expected that the aging population of the United States will contribute to an increased incidence of respiratory conditions, such as COPD and pneumonia. ${ }^{5}$ Respiratory therapists play and will continue to play an important role in a team-based health-care approach.

The recurrent challenge for IPE domain integration is largely due to discipline-specific curricula, content saturation, and at times resistance to fully integrating interprofessional experiences. ${ }^{6}$ Faculty attitudes and knowledge of IPE in other health professional programs have been evaluated previously..$^{7-9}$ In this study, knowledge refers to IPE implementation and definition. Faculty attitudes are the personal perception of individual institutions, programs, and their colleagues' ability to implement IPE within RT. Support for IPE within individual programs is also evaluated. Previous studies among pharmacy, osteopathic medicine, and physician assistant faculty have reported barriers to IPE implementation due to limited access to other health-care disciplines, the lack of adequate clinical training sites, lack of administrative support, insufficient faculty resources, lack of standardized assessment tools, and little flexibility within curriculum requirements. ${ }^{10,11}$

Reeves et al ${ }^{12}$ call for additional studies in professionspecific IPE interventions, randomized control trials, and qualitative measures involving IPE and practice changes, and cost-benefit analysis to efficiently expand this field. American health-care educational accrediting bodies currently lack a collective mandate for IPE, although an evaluation found that most programs, such as nursing, used some form of interprofessional language in their accrediting standards. ${ }^{13}$

The main goal of this study was to determine the knowledge, attitudes, and perceived importance regarding IPE program implementation across all RT faculty. Betweengroup assessment of associate's and bachelor's/master's program faculty and profit and nonprofit institution faculty further describe IPE practice and perspectives.

\section{Methods}

\section{Study Design}

A single-stage anonymous questionnaire with 2 reminders was sent via e-mail to RT faculty in the United States,

\section{QUICK LOOK}

\section{Current knowledge}

Interprofessional education (IPE) utilizes a collaborative approach to introduce competencies in communication, teamwork, roles and responsibilities, and ethical practice within health-care teams. Respiratory therapy (RT) programs incorporate IPE in education practice, but little is known about faculty knowledge, attitudes toward IPE, and the current practices of different RT programs.

\section{What this paper contributes to our knowledge}

This study demonstrates that a majority of RT faculty in accredited programs recognize the importance of IPE and incorporate some form of interprofessional instruction in their programs. There were significant differences between faculty in associate's and bachelor's/master's degree programs on attitudes about IPE in academic settings, but they were in agreement on the importance of interprofessional practice in health-care teams.

employed at Committee on Accreditation for Respiratory Care-accredited institutions.

\section{Study Population}

In November 2015, we utilized the Committee on Accreditation for Respiratory Care directory, available online, to retrieve the names and e-mail addresses of the program directors of all RT programs with continuing accreditation $(n=375)$, probationary accreditation $(n=14)$, or provisional accreditation status $(n=27)$. By using the affiliations from program directors' e-mail addresses, we identified the corresponding website of each of the RT programs and then retrieved the information of the other faculty affiliated with that program excluding preceptors. Programs with inactive or withdrawn accreditation, satellite campus, and polysomnography were excluded.

\section{Survey Development}

A 42-question survey was designed based on previously validated questionnaires, assessing faculty perception of IPE among health-care faculty, and adapted for the RT discipline. ${ }^{7,9}$ The survey comprised 6 sections. Section 1 (5 questions) collected general information about RT programs, such as the size of the program (number of students enrolled), type of school (community college, technical college, private/public universities), nonprofit status, degree awarded (AS/AAS, BSc/MSc), and length of program 


\section{INTERPROFESSIONAL EDUCATION IN RESPIRATORY THERAPY}

existence in years. Choices for program sizes were based on the 25th, interquartile range (25th-75th), 75th, and 90th percentiles of all accredited program enrollments according to data from the Committee on Accreditation for Respiratory Care (www.coarc.com, Accessed October 20, 2015). The survey also asked about collaborations with other disciplines for IPE. Section 2 (8 questions) examined knowledge about IPE and current inclusion of IPE in curricula. Faculty were asked to describe their use of a variety of interprofessional instructional methods as never, rarely, most of time, or always. Agreement with the World Health Organization's definition of IPE was assessed, and beliefs about the number of credit hours necessary for IPE instruction were also evaluated. ${ }^{14}$ Questions were organized to address the IPE competencies (values and ethics, roles and responsibilities, communication, and teamwork), as determined by the Interprofessional Education Collaborative Expert Panel. ${ }^{4}$ Respondents were able to rank the competencies on a 1-4 scale, with 1 being the most important. Each ranking order could only be used once. The next 3 sections are an adaptation from Curran et al ${ }^{7}$; questions focused on clinical care were omitted. The 3 included scales were attitudes toward IPE (9 questions), attitudes about interprofessional learning in the academic setting (12 questions), and attitudes toward interprofessional learning in health-care teams ( 8 questions). In these sections (sections 3-5), responses were determined using a 5-point Likert scale where $1=$ strongly disagree and $5=$ strongly agree.

\section{Administration of the Survey}

Qualtrics 1/2016 (Qualtric Labs, Provo, Utah), an online questionnaire software, was used to create the survey for online distribution as a single anonymous survey with 2 reminders. To assess feasibility and functionality of the survey instrument, a pilot test invitation e-mail was sent to a random subsample of 50 faculty. The survey took an average of $13.7 \mathrm{~min}$ to complete among participants who completed the survey at one sitting. Following initial evaluation and process evaluation, the survey was distributed via e-mail to the remaining $824 \mathrm{RT}$ faculty. Based on pilot test results, respondents were informed that the survey was estimated to take approximately $15 \mathrm{~min}$ to complete. To increase the survey return rate, 2 reminder emails were sent at 2 weeks and 4 weeks to faculty who did not complete the survey. In total, the survey was kept open for 8 weeks. Investigators received no identifying information.

\section{Data Analysis}

Data were analyzed using SPSS 23.0 (IBM Corp, Armonk, New York); all collected data were inspected for error, including outliers. The data were also analyzed for normality and response bias by searching for a pattern of extreme responses or consistently neutral responses (I don't know/have no opinion/prefer not to answer) with no deviations detected. To test the reliability of the edited scales from Curran et al, ${ }^{7}$ Cronbach's $\alpha$ was conducted separately on each of the final 3 sections, as recommended by previous research. ${ }^{15}$

Demographics were analyzed by frequencies of responses, and group differences were assessed by chi-square. Chi-square and the Mann-Whitney U test compared the non-parametric questionnaire responses across the different subgroups. Significance level was tested against $\alpha=.05$.

Current collaborations with other health education disciplines and RT programs were analyzed by TagCrowd (www.tagcrowd.com) to generate a word cloud visually representing the frequency of different health discipline collaborations listed by respondents. Similar program names were converted to a single name. This project was approved by the institutional review board at Augusta University (Augusta, Georgia).

\section{Results}

Overall, 285 of 874 possible faculty respondents completed the survey for a total response rate of $33 \%$. This is a better response than that for similar internet survey research using an e-mailed survey link among faculty, which was reported to be around 20\%.16,17 More than half of the respondents $(n=197,69 \%)$ identified themselves as faculty at an associate's only program, whereas the remaining faculty $(n=88,31 \%)$ worked at programs that awarded a bachelor's and/or master's degree. Faculty at nonprofit institutions comprised $83 \%(n=237)$ of the sample. Table 1 summarizes the demographic characteristics of the respondents' RT programs. Significant group differences were found between profit status and age of the program (chi-square $=21.51, P=.02$ ). When compared by degree offered, type of institution (chi-square $=185.85, P<.001$ ), number of students enrolled (chi-square $=35.1, P<.001$ ), and age of the program were all significantly different between groups (chi-square $=11.0, P<.05$ ) .

In section 2 , faculty reported using interprofessional instructional methods, including case studies $(n=54,38 \%)$, clinic $(n=78,55 \%)$, and simulation $(n=92,64.8 \%)$, most often. A combination of methods was reported by $55 \%(n=78)$ of the faculty. No significant differences existed between faculty responses by degree offered or profit status in this section.

Current health discipline academic programs collaborating with RT faculty are shown in Figure 1 . The most frequently listed collaborating program was nursing ( $n=217,79 \%$ of responses). We provided 8 choices of collaborating disciplines (nursing, pharmacy, dietetics, physical therapy, occupational therapy, medicine, social 
Table 1. Respondent Demographic Characteristics

\begin{tabular}{|c|c|c|c|c|c|c|}
\hline \multirow[b]{2}{*}{ Variables } & \multirow{2}{*}{$\begin{array}{c}\text { Total } \\
(N=285), n(\%)\end{array}$} & \multicolumn{2}{|c|}{ Degree Offered, $n(\%)$} & \multicolumn{3}{|c|}{ Profit Status, $n(\%)$} \\
\hline & & $\begin{array}{l}\text { Associate's } \\
(n=197)\end{array}$ & $\begin{array}{c}\text { Bachelor's/Master's } \\
\quad(n=88)\end{array}$ & $\begin{array}{l}\text { For Profit } \\
(n=41)\end{array}$ & $\begin{array}{l}\text { Nonprofit } \\
(n=237)\end{array}$ & $\begin{array}{l}\text { Unknown } \\
(n=7)\end{array}$ \\
\hline \multicolumn{7}{|l|}{ Type of institution } \\
\hline Community, junior, technical college & $167(58.6)$ & $160(95.8)$ & $7(4.2)$ & $25(15.0)$ & $136(81.4)$ & $6(3.6)$ \\
\hline Liberal arts college & $3(1.1)$ & $0(0)$ & $3(100.0)$ & $1(33.3)$ & $2(66.7)$ & $0(0)$ \\
\hline Technical college & $19(6.7)$ & $18(94.7)$ & $1(5.3)$ & $8(42.1)$ & $11(57.9)$ & $0(0)$ \\
\hline Private university & $26(9.1)$ & $9(34.6)$ & $17(65.4)$ & $2(7.7)$ & $23(88.5)$ & $1(3.8)$ \\
\hline Public university & $60(21.1)$ & $6(10.0)$ & $54(90.0)$ & $4(6.7)$ & $56(93.3)$ & $0(0)$ \\
\hline Other & $9(3.2)$ & $4(44.4)$ & $5(55.6)$ & $1(11.1)$ & $8(88.9)$ & $0(0)$ \\
\hline Prefer not to answer & $1(0.4)$ & $0(0)$ & $1(100.0)$ & $0(0)$ & $1(100)$ & $0(0)$ \\
\hline \multicolumn{7}{|l|}{ Profit status } \\
\hline Not for profit & $237(83.2)$ & $158(66.7)$ & $79(33.3)$ & & & \\
\hline For profit & $41(14.4)$ & $33(80.5)$ & $8(19.5)$ & & & \\
\hline Prefer not to answer & $7(2.5)$ & $6(85.7)$ & $1(14.3)$ & & & \\
\hline \multicolumn{7}{|l|}{ Enrolled students } \\
\hline$<13$ & $16(5.6)$ & $13(81.3)$ & $3(18.8)$ & $2(12.5)$ & $13(81.3)$ & $1(6.3)$ \\
\hline $13-20$ & $51(17.9)$ & $45(88.2)$ & $6(11.8)$ & $10(19.6)$ & $39(76.5)$ & $2(3.9)$ \\
\hline $20-25$ & $32(11.2)$ & $28(87.5)$ & $4(12.5)$ & $5(15.6)$ & $27(84.4)$ & $0(0)$ \\
\hline $25-30$ & $40(14.0)$ & $33(82.5)$ & $7(17.5)$ & $5(12.5)$ & $34(85.0)$ & $1(2.5)$ \\
\hline$>30$ & $146(51.2)$ & $78(53.4)$ & $68(46.6)$ & $19(13.0)$ & $124(84.9)$ & $3(2.1)$ \\
\hline \multicolumn{7}{|l|}{ Age of program } \\
\hline$<5 \mathrm{y}$ & $11(3.9)$ & $10(90.9)$ & $1(9.1)$ & $3(27.3)$ & $7(63.6)$ & $1(9.1)$ \\
\hline $5-10 y$ & $29(10.2)$ & $21(72.4)$ & $8(27.6)$ & $10(34.5)$ & $18(62.1)$ & $1(3.4)$ \\
\hline $10-15 y$ & $15(5.3)$ & $13(86.7)$ & $2(13.3)$ & $4(26.7)$ & $10(66.7)$ & $1(6.7)$ \\
\hline $15-20 y$ & $16(5.6)$ & $14(87.5)$ & $2(12.5)$ & $3(18.8)$ & $13(81.3)$ & $0(0)$ \\
\hline$>20 y$ & $213(74.7)$ & $139(65.3)$ & $74(34.7)$ & $21(9.9)$ & $188(88.3)$ & $4(1.9)$ \\
\hline Prefer not to answer & $1(0.4)$ & $0(0)$ & $1(100)$ & $0(0)$ & $1(100.0)$ & $0(0)$ \\
\hline
\end{tabular}

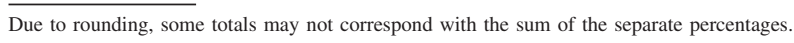

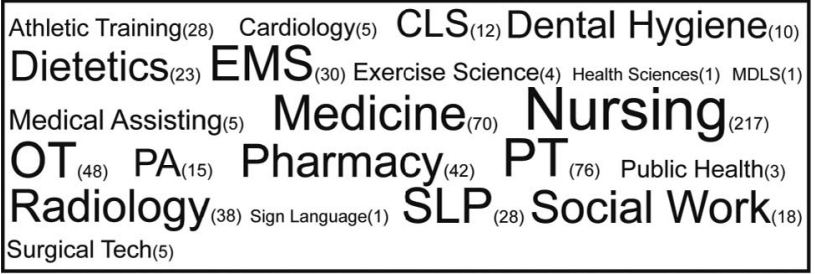

Fig. 1. Professions currently collaborating with respiratory therapy programs in interprofessional education. The current collaborating health discipline academic programs listed by the survey respondents were compiled, and similar programs were renamed to a single title. This file was uploaded into TagCrowd (www.tagcrowd. com) to generate a word cloud. The size of the word visually represents the frequency with which the word appears in the file. Actual frequencies are noted next to the word in parentheses. $\mathrm{CLS}=$ clinical laboratory science; EMS = emergency medical services; HIT = health information technology; MDLS = medical and digital laboratory sciences; OT = occupational therapy; PA = physician's assistant; PT = physical therapy; SLP = speech and language pathology.

work, and speech-language pathologist), including the allowance of the option to add a non-listed collaboration: 15 additional professions were suggested. Twenty-two respondents reported no collaborating discipline.
Slightly more than half of faculty $(n=144,53 \%)$ indicated that their programs included some form of IPE training. However, more faculty in bachelor' s/master's programs $(n=55,65.5 \%)$ reported IPE inclusion than associate's degree faculty $(n=89,48 \%$, chi-square $=7.224$, $P=.007)$. Profit status did not result in significant differences in inclusion of IPE training.

Responses to the question "In your opinion, how many credit hours are needed to teach IPE?" varied: $5 \%(n=15)$ for $1 \mathrm{~h}, 9 \%$ for $2 \mathrm{~h}(n=25), 13 \%$ for $3 \mathrm{~h}(n=37)$, and $15 \%$ for $\geq 4 \mathrm{~h}(n=42)$. Seven percent indicated $0 \mathrm{~h}$ $(n=18)$, and "I don't know" was selected by $48 \%(n=124)$. Further analysis by degree awarded and profit status did not find significant differences between groups.

Almost $80 \%$ of faculty respondents $(n=207)$ agreed that they would like to see a greater emphasis on IPE in curricula. This was not statistically different across groups. Forty percent of all faculty responses agreed that current accreditation requirements limit IPE efforts.

Faculty were asked to rank the IPE competencies (ethics, communication, roles and responsibilities, and teams and teamwork) from most to least important on a scale of 1-4. Overall, communication was ranked as the most im- 


\section{INTERPROFESSIONAL EDUCATION IN RESPIRATORY THERAPY}

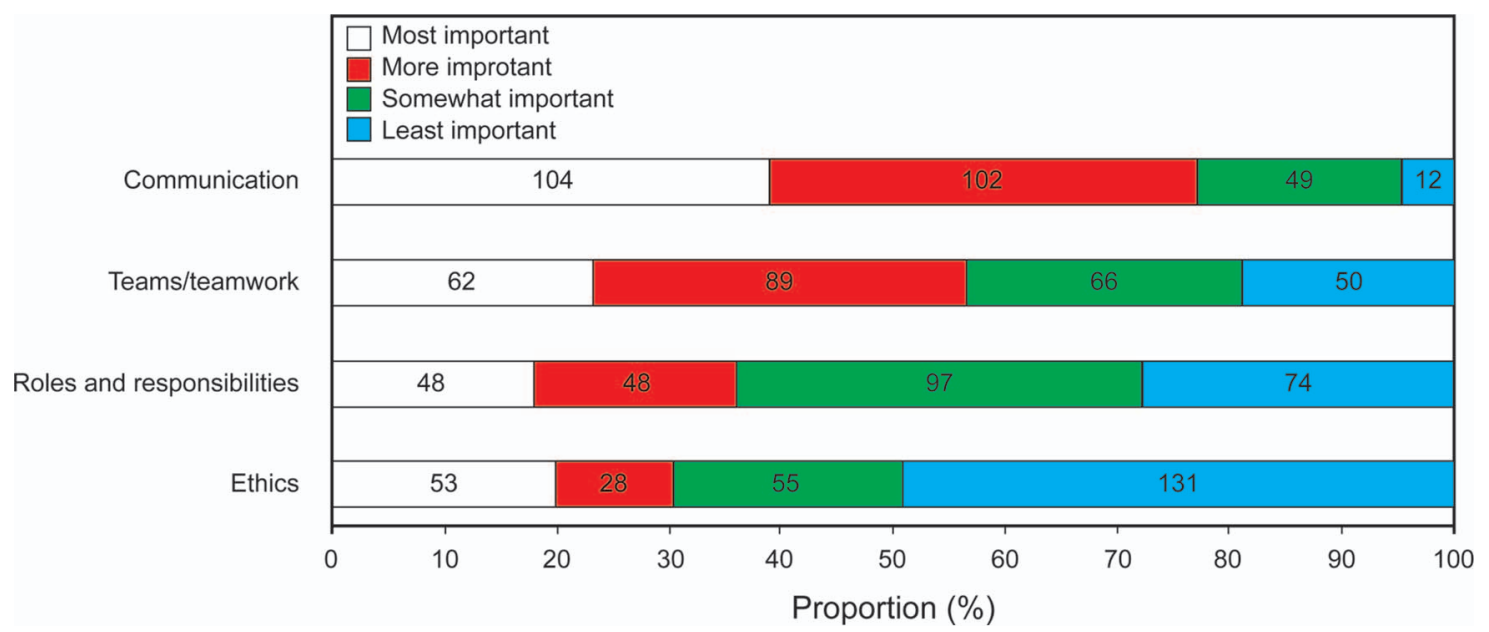

Fig. 2. Overall rankings of interprofessional education competency importance. Survey respondents were asked to rank the importance of the 4 competencies recommended by the IPEC Task Force: ethics, communication, roles and responsibilities, and teams/teamwork. Each item was ranked on a scale of 1 (most important) to 4 (least important), and each rank could only be used once. Responses are depicted in a stacked bar graph, and total numbers of responses are listed in each section of the bar.

Table 2. Rankings of Interprofessional Education Competency Importance by Degree Offered and Chi-Square Tests of Group Differences

\begin{tabular}{|c|c|c|c|c|c|}
\hline Competencies & $\begin{array}{c}\text { Most } \\
\text { Important }\end{array}$ & $\begin{array}{c}\text { More } \\
\text { Important }\end{array}$ & $\begin{array}{l}\text { Somewhat } \\
\text { Important }\end{array}$ & $\begin{array}{c}\text { Least } \\
\text { Important }\end{array}$ & $P$ \\
\hline Ethics & & & & & .20 \\
\hline Associate's & $10(23.1)$ & $17(9.1)$ & 37 (19.9) & $89(47.8)$ & \\
\hline Bachelor's/master's & $10(12.3)$ & $11(13.6)$ & $18(22.2)$ & $42(51.9)$ & \\
\hline Communication & & & & & .71 \\
\hline Associate's & $72(38.7)$ & $68(36.6)$ & $37(19.9)$ & $9(4.8)$ & \\
\hline Bachelor's/master's & $32(39.5)$ & $34(42.0)$ & $12(14.8)$ & $3(3.7)$ & \\
\hline Roles and responsibilities & & & & & .18 \\
\hline Associate's & $35(18.8)$ & $39(21.0)$ & $65(34.9)$ & $47(25.3)$ & \\
\hline Bachelor's/master's & $13(16.0)$ & $9(11.1)$ & $32(39.5)$ & $27(33.3)$ & \\
\hline Teams/teamwork & & & & & .054 \\
\hline Associate's & $36(19.4)$ & $62(33.3)$ & $47(25.3)$ & $41(22.0)$ & \\
\hline Bachelor's/master's & $26(32.1)$ & $27(33.3)$ & $19(23.5)$ & $9(11.1)$ & \\
\hline
\end{tabular}

portant competency by 104 faculty (39\%). Teams and teamwork was ranked most important by 62 faculty $(23 \%)$, ethics by $53(20 \%)$, and roles and responsibility by 48 $(18 \%)$. Ethics was ranked least important most often $(n=131,49 \%)$ (Fig. 2).

Table 2 presents competency ranking grouped by degree offered. Teams and teamwork was ranked significantly different by associate's versus bachelor's/master's faculty $(P=.054)$. More bachelor's/master's faculty ranked it most important, and more associate's faculty ranked it least important. Ethics, communication, and roles and responsibilities were not ranked significantly differently by faculty in these groups.

In Table 3, faculty at for-profit institutions significantly rank ethics as most important, compared to faculty at non- profit institutions $(P=.02)$. All other IPE competency rankings were not significantly different between profit and nonprofit institutions.

Table 4 summarizes the responses to the individual items of sections 3-5 across the overall sample. Mann-Whitney/Wilcoxon tests between groups by degree offered and profit/nonprofit status indicated that there were significant differences between faculty responses by degree offered; no significant differences were found between respondents in the profit/nonprofit group. Group differences on these sections are reported in supplementary Tables 1 and 2 (see the supplementary materials at http://www.rcjournal.com).

Cronbach's $\alpha$ revealed high internal consistency within sections 3-5: attitudes toward IPE (0.78), attitudes toward interprofessional learning in the academic setting (0.74), 
INTERPROFESSIONAL EDUCATION IN RESPIRATORY THERAPY

Table 3. Faculty Rankings of Interprofessional Education Competency Importance by Profit Status of Institution, by Total Individual Response

\begin{tabular}{|c|c|c|c|c|c|}
\hline Competencies & $\begin{array}{c}\text { Most } \\
\text { Important }\end{array}$ & $\begin{array}{c}\text { More } \\
\text { Important }\end{array}$ & $\begin{array}{l}\text { Somewhat } \\
\text { Important }\end{array}$ & $\begin{array}{c}\text { Least } \\
\text { Important }\end{array}$ & $P$ \\
\hline Ethics & & & & & .02 \\
\hline Nonprofit & $37(16.7)$ & $24(10.8)$ & $51(23.0)$ & $110(49.5)$ & \\
\hline For profit & $14(36.8)$ & $3(7.9)$ & $4(10.5)$ & $17(44.7)$ & \\
\hline Communication & & & & & .92 \\
\hline Nonprofit & $89(40.1)$ & $83(37.4)$ & $40(18.0)$ & $10(4.5)$ & \\
\hline For profit & $13(34.2)$ & $16(42.1)$ & $7(18.4)$ & $2(5.3)$ & \\
\hline Roles and responsibilities & & & & & .45 \\
\hline Nonprofit & $40(18.0)$ & $38(17.1)$ & $78(35.1)$ & $66(29.7)$ & \\
\hline For profit & $6(15.8)$ & $8(21.1)$ & $17(44.7)$ & $7(18.4)$ & \\
\hline Teams/teamwork & & & & & .09 \\
\hline Nonprofit & $56(25.2)$ & $77(34.7)$ & $53(23.9)$ & $36(16.2)$ & \\
\hline For profit & $5(13.2)$ & $11(28.9)$ & $10(26.3)$ & $12(31.6)$ & \\
\hline
\end{tabular}

and attitudes toward interprofessional learning in healthcare teams $(0.88)$.

In section 3 (attitudes toward IPE), overall, responses supported IPE; there were no significant differences between groups. Over $90 \%$ of faculty strongly agreed or agreed that patients would ultimately benefit from students who receive IPE training and that RT students would benefit from interdisciplinary IPE training.

In section 4 (attitudes toward interprofessional learning in the academic setting), in general, $42 \%(n=109)$ of faculty did not think that there was room for additional IPE education requirements in the current curriculum, and $34 \%(n=88)$ neither agreed nor disagreed. Respondents ( $n=226,88 \%)$ agreed or strongly agreed that faculty should be encouraged to participate in interprofessional courses.

Faculty were evenly divided overall and between groups on whether the Committee on Accreditation for Respiratory Care should mandate IPE inclusion in the RT curriculum, although $80 \%$ felt that IPE was important. Bachelor's and master's degree faculty agreed more frequently that there are current curriculum requirements that could be removed to make room for additional IPE education, though this is not significant.

Several statements in this section received significantly different responses between the associate's and bachelor's/master's groups: "There are current curriculum requirements that could be removed to make room for additional IPE education," with more associate's faculty disagreeing with the statement $(P=.02)$; "My program has the resources and personnel to teach IPE courses," with more associate's faculty disagreeing with the statement $(P<.001)$; "My institution has the resources to implement IPE," with more associate's faculty disagreeing with the statement $(P<.001)$; "Faculty should be encouraged to participate in interprofessional courses," with more associate's faculty agreeing with the statement $(P=.031)$; "Faculty like teaching with faculty from other academic departments," with more bachelor's/master's faculty agreeing with the statement $(P=.002)$; and "It is important for academic health center campuses to provide interprofessional learning opportunities" $(P<.001)$, with more bachelor's/master's agreeing with the statement. (see supplementary Tables 1 and 2.)

In section 5 (attitudes toward interprofessional learning in health-care teams), faculty responses reflected support for interprofessional practice in health care, the belief that patients are more likely to be treated as a whole person (77\%), that patient care delivery is more efficient (81\%), that care improves in quality with interprofessional practice (87\%), and that working in an interprofessional environment keeps health-care professionals enthusiastic about their jobs (70\%). Significant differences between degreeawarded groups exist for the statement: "Team meetings foster communication among members from different professions or disciplines" $(P=.02)$.

\section{Discussion}

The main goal of this study was to determine the attitudes and perceived importance of IPE program implementation across all RT faculty. In general, faculty responses indicate strong supportive attitudes toward IPE, but respondents remain unsure of administration support and available institutional resources. Faculty responses indicate a positive perception and a recognition of the importance of IPE within the RT curriculum, with a majority preferring a greater emphasis on IPE in the curriculum and a regular inclusion of IPE in half of institution programs. Half of the population surveyed did not have an opinion on 


\section{INTERPROFESSIONAL EDUCATION IN RESPIRATORY THERAPY}

Table 4. Likert Scale Questions and Responses: Total Sample

\begin{tabular}{|c|c|c|c|c|c|}
\hline Questions & $\begin{array}{l}\text { Strongly } \\
\text { Agree }\end{array}$ & Agree & $\begin{array}{l}\text { Neither Agree } \\
\text { nor Disagree }\end{array}$ & Disagree & $\begin{array}{l}\text { Strongly } \\
\text { Disagree }\end{array}$ \\
\hline \multicolumn{6}{|l|}{ Attitudes toward IPE } \\
\hline $\begin{array}{l}\text { Interprofessional learning will help students think positively about } \\
\text { other health care professionals. }\end{array}$ & $147(56)$ & $107(41)$ & 7 (3) & $0(0)$ & $0(0)$ \\
\hline $\begin{array}{l}\text { Clinical problem solving can only be learned effectively when students } \\
\text { are taught within their individual department/school. }\end{array}$ & $16(6)$ & $29(11)$ & $42(16)$ & $147(56)$ & $27(10)$ \\
\hline $\begin{array}{l}\text { Patients would ultimately benefit if health care students worked } \\
\text { together to solve patient problems. }\end{array}$ & $164(63)$ & $91(35)$ & $5(2)$ & $1(1)$ & $0(0)$ \\
\hline $\begin{array}{l}\text { Students in RT would benefit from working on small-group projects } \\
\text { with other health care students. }\end{array}$ & $132(51)$ & $106(41)$ & $21(8)$ & $2(<1)$ & $0(0)$ \\
\hline $\begin{array}{l}\text { Communication skills should be learned with integrated classes of } \\
\text { health-care students. }\end{array}$ & $112(43)$ & 115 (44) & $32(12)$ & $2(1)$ & $0(0)$ \\
\hline $\begin{array}{l}\text { Learning with students in other health professional schools helps } \\
\text { students to become more effective members of a health-care team. }\end{array}$ & $144(55)$ & $109(42)$ & $8(3)$ & $0(0)$ & $0(0)$ \\
\hline $\begin{array}{l}\text { Interprofessional learning among health-care students will increase their } \\
\text { ability to understand clinical problems. }\end{array}$ & $123(47)$ & $119(46)$ & $17(6)$ & $2(1)$ & $0(0)$ \\
\hline $\begin{array}{l}\text { Interprofessional learning will help students to understand their } \\
\text { own professional limitations. }\end{array}$ & $96(37)$ & $128(49)$ & $32(12)$ & $4(1)$ & $1(<1)$ \\
\hline $\begin{array}{l}\text { For small-group learning to work, students need to trust and respect } \\
\text { each other. }\end{array}$ & $142(54)$ & $105(40)$ & $13(5)$ & $1(1)$ & $0(0)$ \\
\hline \multicolumn{6}{|l|}{$\begin{array}{l}\text { Attitudes and beliefs about interprofessional learning in the academic } \\
\text { setting }\end{array}$} \\
\hline $\begin{array}{l}\text { There are current curriculum requirements that could be removed to } \\
\text { make room for additional IPE education. }\end{array}$ & $21(8)$ & $39(15)$ & $88(34)$ & $70(27)$ & 39 (15) \\
\hline CoARC should mandate IPE in the RT curriculum. & $19(7)$ & $58(23)$ & $91(35)$ & $55(21)$ & $34(13)$ \\
\hline My program has the resources and personnel to teach IPE courses. & $36(14)$ & $104(40)$ & $56(22)$ & $49(19)$ & $12(5)$ \\
\hline My institution has the resources to implement IPE. & $43(17)$ & $110(43)$ & $69(27)$ & $28(11)$ & $7(3)$ \\
\hline Interprofessional learning better utilizes resources. & $49(19)$ & $117(45)$ & $80(31)$ & $9(4)$ & $2(1)$ \\
\hline Faculty should be encouraged to participate in interprofessional courses. & $73(28)$ & $153(59)$ & $27(11)$ & $2(1)$ & $2(1)$ \\
\hline Faculty like teaching with faculty from other academic departments. & $31(12)$ & $108(42)$ & $97(38)$ & $19(7)$ & $2(1)$ \\
\hline Interprofessional efforts weaken program content. & $53(21)$ & $149(58)$ & $41(16)$ & $10(4)$ & $4(2)$ \\
\hline Interprofessional efforts require support from campus administration. & $110(43)$ & $112(44)$ & $26(10)$ & $9(3)$ & $0(0)$ \\
\hline Interprofessional courses are logistically difficult. & $3(1)$ & $29(11)$ & $78(30)$ & $96(37)$ & $51(20)$ \\
\hline Accreditation requirements limit interprofessional efforts. & $11(4)$ & $59(23)$ & $107(42)$ & $66(26)$ & $14(5)$ \\
\hline $\begin{array}{l}\text { It is important for academic health center campuses to provide } \\
\text { interprofessional learning opportunities. }\end{array}$ & $63(24)$ & $140(54)$ & $47(18)$ & $7(3)$ & $0(0)$ \\
\hline \multicolumn{6}{|l|}{ Attitudes toward interprofessional learning in health care teams } \\
\hline $\begin{array}{l}\text { Patients/clients receiving interprofessional care are more likely than } \\
\text { others to be treated as whole persons. }\end{array}$ & $82(32)$ & $116(45)$ & $52(20)$ & $6(2)$ & $0(0)$ \\
\hline $\begin{array}{l}\text { The give and take among team members helps them make better } \\
\text { patient/client care decisions. }\end{array}$ & $89(35)$ & $141(55)$ & $24(9)$ & $2(<1)$ & $0(0)$ \\
\hline $\begin{array}{l}\text { The interprofessional approach makes the delivery of care more } \\
\text { efficient. }\end{array}$ & $77(30)$ & $130(51)$ & $43(17)$ & $6(2)$ & $0(0)$ \\
\hline $\begin{array}{l}\text { Working in an interprofessional environment keeps most health } \\
\text { professionals enthusiastic and interested in their jobs. }\end{array}$ & $58(23)$ & $120(47)$ & $77(30)$ & $1(<1)$ & $0(0)$ \\
\hline $\begin{array}{l}\text { The interprofessional approach improves the quality of care to } \\
\text { patients/clients. }\end{array}$ & $111(43)$ & $113(44)$ & $32(12)$ & $0(0)$ & $0(0)$ \\
\hline $\begin{array}{l}\text { Having to report observations to a team helps team members better } \\
\text { understand the work of other health professionals. }\end{array}$ & $102(40)$ & $139(54)$ & $14(5)$ & $1(<1)$ & $0(0)$ \\
\hline $\begin{array}{l}\text { Team meetings foster communication among members from } \\
\text { different professions or disciplines. }\end{array}$ & $104(41)$ & $138(54)$ & $13(5)$ & $1(<1)$ & $0(0)$ \\
\hline $\begin{array}{l}\text { Working in an interprofessional manner unnecessarily complicates } \\
\text { things most of the time. }\end{array}$ & $13(5)$ & $15(6)$ & $43(17)$ & $138(54)$ & 47 (18) \\
\hline \multicolumn{6}{|l|}{$\begin{array}{l}\text { Results are } n(\%) \\
\text { IPE }=\text { interprofessional education } \\
\text { CoARC }=\text { Committee on Accreditation for Respiratory Care } \\
\text { RT }=\text { respiratory therapy }\end{array}$} \\
\hline
\end{tabular}


the number of credit hours needed to teach IPE to RT students, indicating a possible lack of knowledge about IPE instructional methods and/or a possible intervention avenue.

Faculty reported that interprofessional education experiences have included involvement with other programs for a number of other disciplines, with nursing identified as the most frequent collaboration. A majority also felt that IPE efforts weaken program content, although they strongly support interprofessional care in patient care and practice. This unexpected result may be due to concerns about curriculum requirements and lack of resources to include additional instruction within programs. This also indicates a potential barrier to implementation of IPE.

Faculty ranked the IPE competencies communication and teamwork highest of the four, demonstrating the importance of IPE as part of an interdisciplinary health-care team. In practice, lack of communication is cited as the main problem area in medical error occurrence. ${ }^{18,19}$ Varying practice settings may require a range of RT skills, which may explain why roles and responsibilities was not ranked as highly among the 4 options, although it was recognized as important. Developing an ethical practice is most likely emphasized outside of IPE settings, which is illustrated by the lower importance ranking.

Differences between faculty respondents in associate's versus bachelor's/master's degree programs existed for inclusion of IPE and among attitudes toward interprofessional learning in the academic setting. Bachelor's and master's faculty reported that they had more access to resources and perceived more encouragement and support from administration for IPE compared with associate's degree faculty responses. This may be in part due to length of the programs, larger institutions housing these programs, and access to additional shared institutional resources, thus enabling more access to IPE implementation opportunities.

To certify a competent workforce, an RT task force has recommended that a bachelor's degree be a prerequisite to sit for the National Board for Respiratory Care Registered Respiratory Therapist licensure exams. ${ }^{20}$ In our study, faculty were evenly divided on whether the Committee on Accreditation for Respiratory Care should mandate IPE inclusion in the RT curriculum, although a large majority felt that IPE was important. The concerns about mandating IPE may be explained by uncertainty over increasing credit hour requirements or the possibility of removing classes from the curriculum.

The Committee on Accreditation for Respiratory Care recognizes difficulty in adding credit hour requirements to curricula and the increasingly complex roles RTs play in health-care settings, as reported in the response to the Coalition for Baccalaureate and Graduate Respiratory Therapy Education white paper on accreditation (www.coarc.com, Ac- cessed March 12, 2016). In addition, the American Association for Respiratory Care Position Statement on Respiratory Therapist Education, revised November $2015,{ }^{21}$ states, "Training and education for entry-to-practice as a respiratory therapist should be provided within programs awarding a bachelor's or master's degree in respiratory care (or equivalent degree titles) and all newly accredited respiratory care educational programs must award, as a minimum, the bachelor's degree in respiratory care (or equivalent degree title)." The Committee on Accreditation for Respiratory Care requirements may move to only accrediting new RT programs that offer a bachelor's degree or higher degree in 2018, as stated in the proposed current policy documents (www.coarc.com/, Accessed March 12, 2016). The responses from faculty in this survey indicate that a longer degree program would enable more opportunities for IPE implementation and more time to devote to IPE. Faculty report that interprofessional education experiences have included involvement with other programs for a number of other disciplines, with nursing identified as the most frequent collaboration.

\section{Limitations of the Study}

Survey research has inherent limitations due to the nature of self-reporting. All results are the opinions of faculty members of the Committee on Accreditation for Respiratory Care member institutions. Due to the anonymous nature of the study, we were unable to evaluate programs individually, which may have led to oversampling at some larger programs. Program directors have different experiences and perspectives from RT faculty, and thus a smaller study was not conducted only with program directors.

To limit non-responses, we set the online survey to forced answers. Information about faculty gender, highest degree, length of time teaching, and clinical experience was not collected. Overall the response rate does limit generalizability of this study. There was significantly greater faculty response from associate's degree-granting programs $(n=188,68.6 \%)$; this was expected because there are more programs accredited in the associate's degree category (85\% of Committee on Accreditation for Respiratory Care-accredited programs). However, our response rate was higher among faculty at bachelor's/master's programs $(n=83,30.6 \%)$ than the $15 \%$ of Committee on Accreditation for Respiratory Care-accredited programs.

\section{Suggestions for Practice, Teaching, and Future Research}

The need for competent and RT professionals who can function in a team environment continues to grow. Collaboration with other health professions is an important 


\section{INTERPROFESSIONAL EDUCATION IN RESPIRATORY THERAPY}

component for RT programs to practice and demonstrate teamwork between students and faculty. Future IPE endeavors should develop and expand partnerships within all other health professions.

These findings provide a baseline of RT faculty knowledge and attitudes toward IPE, which will be instrumental when evaluating future IPE curriculum implementation and IPE interventions. Future implementations of this survey could be used to evaluate the growth of IPE inclusion and attitudes toward IPE in RT programs and the number of discipline collaborations. Committee on Accreditation for Respiratory Care consideration of the bachelor's degree for entry-level practice may enhance opportunities for IPE integration into RT programs. In addition, RT programs may benefit from specific IPE requirements and competency expectations as curriculum requirements are revised. Future studies may also evaluate the reported barriers to and opportunities for IPE in RT programs.

\section{REFERENCES}

1. Steinert Y. Learning together to teach together: Interprofessional education and faculty development. J Interprof Care 2005;19(Suppl 1):60-75.

2. Buring SM, Bhushan A, Broeseker A, Conway S, Duncan-Hewitt W, Hansen L, Westberg S. Interprofessional education: definitions, student competencies, and guidelines for implementation. Am J Pharm Educ 2009;73(4):59.

3. Institute of Medicine. Health professions education: a bridge to quality. Washington, DC: National Academies Press; 2003.

4. Interprofessional Education Collaborative Expert Panel. Core competencies for interprofessional collaborative practice: report of an expert panel. Washington, DC: Interprofessional Education Collaborative; 2011

5. Bureau of Labor Statistics. Occupational outlook handbook, 2014-2015 edition: respiratory therapists. https://www.bls.gov/ooh/healthcare/ respiratory-therapists.htm. Accessed February 10, 2017.

6. Clark PG. What would a theory of interprofessional education look like? Some suggestions for developing a theoretical framework for teamwork training. J Interprof Care 2006;20(6):577-589.

7. Curran VR, Sharpe D, Forristall J. Attitudes of health sciences faculty members towards interprofessional teamwork and education. Med Educ 2007;41(9):892-896.
8. Giordano C, Umland E, Lyons KJ. Attitudes of faculty and students in medicine and the health professions toward interprofessional education. J Allied Health 2012;41(1):21-25.

9. Lash DB, Barnett MJ, Parekh N, Shieh A, Louie MC, Tang TT. Perceived benefits and challenges of interprofessional education based on a multidisciplinary faculty member survey. Am J Pharm Educ 2014;78(10): 180 .

10. Jones KM, Blumenthal DK, Burke JM, Condren M, Hansen R, Holiday-Goodman M, Peterson CD. Interprofessional education in introductory pharmacy practice experiences at US colleges and schools of pharmacy. Am J Pharm Educ 2012;76(5):80.

11. Lash DB, Barnett MJ, Parekh N, Shieh A, Louie MC, Tang TT. Perceived benefits and challenges of interprofessional education based on a multidisciplinary faculty member survey. Am J Pharm Educ 2014;78(10): 180 .

12. Reeves S, Perrier L, Goldman J, Freeth D, Zwarenstein M. Interprofessional education: effects on professional practice and healthcare outcomes (update). Cochrane Database Syst Rev 2013;(3):CD002213.

13. Zorek J, Raehl C. Interprofessional education accreditation standards in the USA: a comparative analysis. J Interprof Care 2013;27(2): 123-130.

14. World Health Organization. Framework for action on interprofessional education and collaborative practice. Geneva: World Health Organization

15. Polit D, Yang F. Measurement and the measurement of change. Baltimore, Maryland: Wolters Kluwer; 2016:142-147.

16. Georgina DA, Olson MR. Integration of technology in higher education: a review of faculty self-perceptions. Internet Higher Educ 2008;11(1):1-8.

17. Kaplowitz MD, Hadlock TD, Levine R. A comparison of web and mail survey response rates. Public Opin Q 2004;68(1):94-101.

18. O'Daniel M, Rosenstein A. Professional communication and team collaboration. In: Hughes RG, editor. Patient safety and quality: an evidence-based handbook for nurses. Rockville, MD: Agency for Healthcare Research and Quality; 2008;33:801-814.

19. Joint Commission on Accreditation of Healthcare Organizations. The Joint Commission guide to improving staff communication. Oakbrook Terrace, IL: Joint Commission Resources; 2005.

20. Barnes TA, Kacmarek RM, Kageler WV, Morris MJ, Durbin CG. Transitioning the respiratory therapy workforce for 2015 and beyond. Respir Care 2011;56(5):681-690.

21. American Association for Respiratory Care. Position Statement on Respiratory Therapist Education; 1998, Revised 2012. https://c.aarc. org/resources/position_statements/documents/rt_education.pdf. Accessed January 25, 2017.

This article is approved for Continuing Respiratory Care Education credit. For information and to obtain your CRCE

(free to AARC members) visit www.rcjournal.com

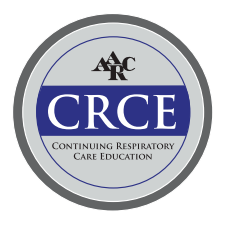

